\title{
Experimental study on formation mechanism of compaction bands in weathered rocks with high porosity
}

\author{
HAN GuoFeng ${ }^{1,2^{*}}$, LIU XiaoLi ${ }^{1} \&$ WANG EnZhi ${ }^{1}$ \\ ${ }^{1}$ State Key Laboratory of Hydroscience and Engineering, Tsinghua University, Beijing 100084, China; \\ ${ }^{2}$ Institute of Mechanics, Chinese Academy of Sciences, Beijing 100190, China
}

Received November 27, 2012; accepted July 30, 2013; published online September 6, 2013

\begin{abstract}
Since Mollema and Antonellini observed compaction bands in the field in 1996, different patterns of compaction bands have been found in laboratory experiments. There are some discrepancies between the laboratory experiments and the field observations: compared to the field observation, the stress levels required to induce compaction bands in laboratory experiments are usually higher than the inferred in the field, and the grain crushing are more intense in the laboratory experiments. In this paper, compaction bands were observed at the maximal principal stresses below $8 \mathrm{MPa}$, which is lower than the stress level inferred in the field, and there was no severe comminution inside the compaction bands. Experimental results indicate that the porosity and confining pressure have great impacts on the types of localization bands. Lower porosity and confining pressure can promote the growth of shear bands and high-angle shear bands. Higher porosity and confining pressure can promote the growth of discrete compaction bands. Intermediate porosity and confining pressure are favorable for the growth of hybrid modes involving two of the three, i.e., discrete compaction band, diffuse compaction band and high-angle shear band. The formation of discrete compaction bands is more unstable compared to diffuse compaction bands. The two types of compaction bands can appear in the same type rocks, and diffuse compaction bands are formed under lower confining pressure compared to discrete compaction bands. The reduction of permeability was within 2 orders of magnitude in this study, and it is $2-3$ orders of magnitude lower than those obtained by other researchers.
\end{abstract}

porous rock, compaction band, permeability evolution

Citation: Han G F, Liu X L, Wang E Z. Experimental study on formation mechanism of compaction bands in weathered rocks with high porosity. Sci China Tech Sci, 2013, 56: 2563-2571, doi: 10.1007/s11431-013-5322-2

\section{Introduction}

Strain localization occurs in different scales in rocks and rock mass. A lot of researchers have studied shear bands in the brittle failure regime of rocks. For the past decade, compaction bands have been identified and investigated in porous rocks as a new form of strain localization. In 1996, Mollema and Antonellini [1] observed some strain localization bands perpendicular to the speculated maximum principal stress in Navajo sandstone in southern Utah and

\footnotetext{
*Corresponding author (email: hgf_xg@126.com)
}

named them as a compaction band. A compaction band is a tabular structure sub-perpendicular to the maximum principal stress without obvious shear strain. Inside the band, grain crushing and pore collapse are severe. Outside the band, there are few cracks. It is a deformation localization structure that occurs in the brittle-ductile transition regime of clastic sedimentary rocks with porosity exceeding about $16 \%$ [2-4].

Since the compaction band was found in the field, some researchers have observed the same appearance later. Olsson et al. [5, 6], Wong et al. [7], Haimson et al. [8-11], Baud et al. [2] and Fôrtin et al. [12] observed three different pat- 
terns of compaction bands in laboratory experiments [3]. Olsson and Holcomb [5, 6] observed wide compaction bands in Castlegate sandstone, which grew in thickness with increasing axial load until the entire specimen was covered. Wong and Townend et al. [7, 13, 14] observed narrow compaction bands, which were only a few grains wide. The bands spread across the specimen with increasing applied load, and were interlayered with less deformed materials. Fôrtin et al. [12], Stanchits et al. [15] and Charalampidou et al. [16] conducted experiments with notched specimens, and observed compaction bands under lower stress levels. The third pattern of compaction bands was observed in specimens with a hole which created a heterogeneous stress field. The band was a single structure with a thickness of 5-10 grains diameter and propagated in its own plane [8-11]. It is believed that high porosity and appropriate confining pressure are necessary for compaction bands formation. But people are still not clear about the reason of different patterns of compaction bands, the relations among them, and the underlying factors.

The formation of compaction bands could break grains and collapse pores, which would change the permeability of rocks. The experiments of Holcomb and Olsson [17], and Vajdova et al. [18] indicated that the permeability is reduced by two to three orders of magnitude during the formation of compaction bands, and they can form a barrier to flow. The movement of underground fluid can change the effective stress of formation, which may lead to forming compaction bands. Thus, it greatly degrades the permeability. Therefore, compaction bands have great economic potential in the industries of oil and gas reservoirs, underground repository for radioactive waste and sequestration of $\mathrm{CO}_{2}[3]$.

Although researchers have found compaction bands in laboratory, which are similar to these in the field, there are some discrepancies between them. The stress levels for the formation of compaction bands in laboratory are higher than that in the field. The damage intensity of grains inside the compaction bands in the field is appreciably lower than that in the laboratory. The thickness of compaction bands in the laboratory is not accordant with that in the field [3, 4]. Sternlof et al. [19] speculated the stress level for forming compaction bands in Aztec sandstone was about 13-54 MPa without considering the pore pressure. The stress levels for forming compaction bands in laboratory are one order of magnitude higher than that in the field, which are about several hundreds MPa [2, 7, 20]. The specimens with notches can form compaction bands at lower stress levels, but they are still above $200 \mathrm{MPa}$ [16, 21-24]. Tembe et al. [25] observed compaction bands at several tens $\mathrm{MPa}$ in Bleurswiller sandstone, which was still at least $20 \mathrm{MPa}$ higher than the inferred stress in the field. Using Tuffeau de Maastricht calcarenite, Baxevanis et al. [26] observed that the compaction bands under the stress levels were closed to the field. Tembe et al. [25] using the data from the field found that the thickness of compaction bands had a quadratic relation with its length. Rudnicki [27] also got the similar results using an anticrack/dislocation model. Tembe et al. [25] using this model found that the stress level for compaction bands formation was inversely proportional to the band thickness. So, they gave a uniform interpretation to the differences of thickness and stress levels between the laboratory and the field. But few compaction bands have been observed at the stress level approximated to that in the field.

Since compaction bands appear in the regime of brittleductile transition, low strength porous rocks may form compaction bands at a lower stress level. In this study, one kind of weathered porous rock with a low strength was selected to conduct conventional triaxial compression tests accompanied by permeability measuring. Discrete compaction bands, high-angle shear bands and hybrid modes composed of two of the three: discrete compaction band, diffuse compaction band and high-angle shear band were gained at very low stress levels. The grain crushing was not severe during the formation of compaction bands, and the permeability reduction was below two orders of magnitude compared with its initial value.

\section{Material and experimental method}

Weathered troctolite was used in this study. This kind of rock before weathered was an ultramafic magmatic rock with phanerocrystalline texture. It consists of $80 \%$ plagioclase and $20 \%$ olivine, and the grain sizes are about one to two millimeters. The weathered rock has high porosity (Table 1), and is relatively homogenous and isotropic in laboratory scale. But there are great differences between different specimens. The grain sizes of weathered rock are dispersive. The big one is on the order of about one millimeter, and the small one is on the order of about $0.1 \mathrm{~mm}$. The pores are large, and the big ones have a dimension of about one millimeter. The cementation of the specimens is quite weak, and the strength is very low. The specimens are cylindrical, the diameters are about $50 \mathrm{~mm}$, and the lengths are variation between 70 to $110 \mathrm{~mm}$. The details of the specimens are listed in Table 1.

Firstly, a layer of adhesive tape was twined around the specimen to avoid the teflon tube punctured. Secondly, the specimen was put on a section of teflon tube with a diameter a little larger than $50 \mathrm{~mm}$. Then, an electric blower was used to make the teflon tube shrinking, making sure that the teflon tube contacted with the specimen tightly. Therefore, the water through the specimen and the oil in the pressure vessel were separated, and the water also could not flow along the specimen's lateral surface. A conventional triaxial test with water flow was conducted at room temperature. The confining pressure applied by silicone oil was between 1 to $3 \mathrm{MPa}$. One end of the specimen was connected with a water pressure of 0.1 to $0.8 \mathrm{MPa}$ and the other end was 
Table 1 Specimen parameters

\begin{tabular}{|c|c|c|c|c|c|c|}
\hline Sample & Diameter $(\mathrm{mm})$ & Length (mm) & Porosity $(\%)$ & Confining pressure $(\mathrm{MPa})$ & Pore pressure $(\mathrm{MPa})$ & Density $\left(\mathrm{g} / \mathrm{cm}^{3}\right)$ \\
\hline 1 & 49.51 & 78.77 & 30.73 & 1.5 & 0.1 & 1.75 \\
\hline 2 & 49.45 & 82.77 & 37.45 & 1.0 & 0.3 & 1.67 \\
\hline 3 & 49.45 & 100.84 & 31.49 & 1.0 & 0.1 & 1.68 \\
\hline 4 & 49.38 & 96.07 & 33.80 & 1.5 & 0.1 & 1.74 \\
\hline 5 & 49.68 & 102.07 & 31.84 & 1.0 & 0.1 & 1.78 \\
\hline 6 & 49.50 & 100.54 & 19.07 & 2.5 & 0.8 & 2.10 \\
\hline 7 & 49.64 & 100.28 & 36.12 & 2.0 & 0.1 & 1.56 \\
\hline 8 & 49.39 & 102.27 & 23.42 & 2.5 & 0.2 & 2.02 \\
\hline 9 & 49.55 & 101.69 & 23.47 & 3.0 & 0.2 & 2.00 \\
\hline 10 & 49.31 & 99.86 & 44.11 & 1.0 & 0.1 & 1.37 \\
\hline
\end{tabular}

exposed to the atmosphere. The axial loading was servocontrolled and applied by displacement during the whole test. When the axial displacement attained the maximal value, the confining pressures of several specimens were unloaded with the fixed axial displacements and permeability was measured. The confining pressure and pore pressure were fixed for every specimen during the whole test except confining unloading tests. The axial displacement was settled after a certain displacement, and the water volume through the specimen can be determined by the displacement of the water vessel piston. By this way the permeability was measured. The axial displacement was measured by an extensometer with four pins. The radial displacement was measured by an extensometer with two pairs of pins, which were located at about the middle of the specimen. Ten specimens were tested in total. Sample 3 was tested firstly. The teflon tube was punctured under the confining pressure, because the surface of the specimen was quite rugged. Therefore, the permeability test of sample 3 failed. Later, a layer of adhesive tape twined around the specimen was used to avoid the teflon tube to be punctured.

In order to investigate the character of rocks under much larger strains, the axial loading, confining pressure and water pressure were unloaded during the tests for samples 4,7 and 10 when the axial displacements were close to the full scale range. After adjusting the extensometers, the confining pressure and water pressure were applied to the values before unloading respectively, and the tests went on. In this paper, this process is named unloading-reloading test, although it is different from the common unloading-reloading test.

Specimens were retrieved from the pressure vessel carefully after the tests. The teflon tubes were exscinded to observe the failure modes.

In this paper, it is assumed that compressive stress and compactive strain are positive, which is in accordance with the common practice in rock mechanics and engineering. The axial stress and strain, confining pressure, lateral strain and pore water pressure are denoted by $\sigma_{1}, \varepsilon_{1}, p_{c}, \varepsilon_{r}$ and $p_{w}$, respectively.

\section{Experimental results and analyses}

\subsection{Mechanical characteristics and failure modes}

Eq. (1) was used to calculate the effective confining pressure, because one side of the specimens was exposed to the atmosphere when permeability was measured. Here, the first peak points of differential stress-axial strain curves, or the points at which the upward slope decreases distinctly are used to calculate the differential stress and effective mean stress of the compactive yield. Because hydrostatic compression test was not carried out, it may be not the shearenhanced compaction point defined by Zhu and Wong [28]. It is much approximate according to previous results [13, 28]. Except sample 7, the points here corresponded to the initial yield points. So, it is appropriate.

$$
p_{\text {eff }}=p_{\mathrm{c}}-0.5 p_{\mathrm{w}} \text {. }
$$

Figure 1 shows some representative curves of the differential stress-axial strain. All of the specimens, except sample 7, have a section of elastic deformation firstly. Then the stresses are overall upward gently or have no obvious overall increase, and punctuated by local stress drops. Sample 7 begins with an overall strain hardening and is punctuated by local stress drops. The differential compactive yield stresses of samples 6, 8 and 9 are 8-11 MPa, and other's are below $5 \mathrm{MPa}$. The terms defined by Baud et al. [2] are used here. A localized structure which is sub-perpendicular to the maximal principal stress is referred to as a compaction band'. The one only a few grains thick (usually fewer than 4 grains) is a 'discrete compaction band', and a structure with a thickness of much more grains is a 'diffuse compaction band'. A localized structure with a relatively high angle $\left(45^{\circ}-80^{\circ}\right)$ to the maximal principal stress is a 'high-angle shear band'.

We summarize the results in Table 2. Comprehensively 

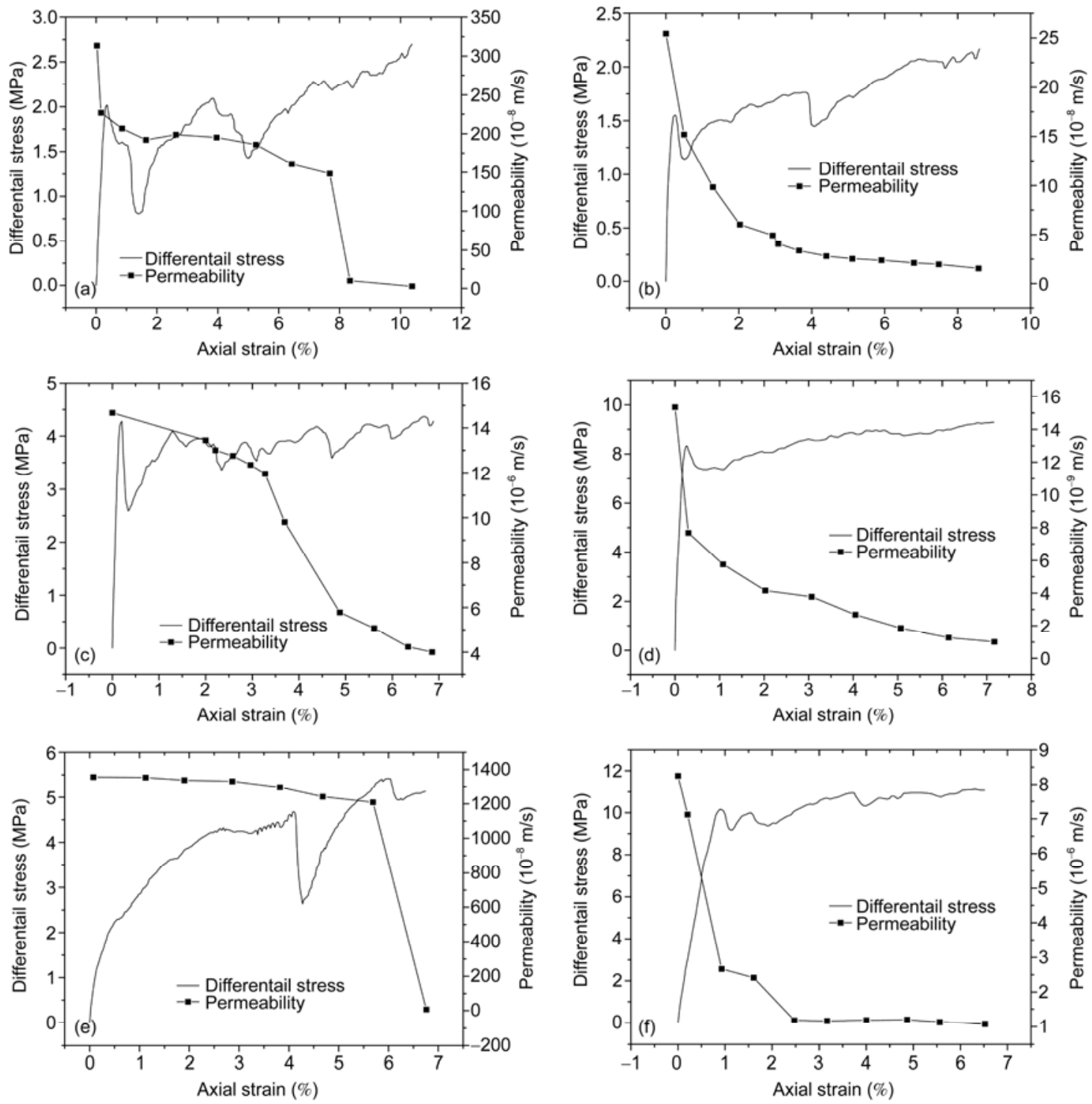

Figure 1 Differential stress and permeability vs. axial strain for (a) sample 1, (b) sample 2, (c) sample 5, (d) sample 6, (e) sample 7 and (f) sample 9.

Table 2 Mechanical results of specimens investigated in this study

\begin{tabular}{|c|c|c|c|c|c|c|}
\hline \multirow{2}{*}{ Sample } & \multirow{2}{*}{$\begin{array}{l}\text { Effective Confining } \\
\text { pressure (MPa) }\end{array}$} & \multicolumn{2}{|c|}{ Compactive yield (MPa) } & \multirow{2}{*}{$\begin{array}{l}\text { Maximum } \\
\text { strain }(\%)\end{array}$} & \multirow{2}{*}{$\begin{array}{c}\text { Initial } \\
\text { Porosity }(\%)\end{array}$} & \multirow{2}{*}{ Failure mode } \\
\hline & & Differential stress & Mean effective stress & & & \\
\hline 1 & 1.45 & 2.04 & 2.13 & 10.40 & 30.73 & $\begin{array}{l}\text { Diffuse compaction band+discrete com- } \\
\text { paction band }\end{array}$ \\
\hline 2 & 0.85 & 1.56 & 1.37 & 8.61 & 37.45 & $\begin{array}{l}\text { Discrete compaction band+high-angle shear } \\
\text { band } 800\end{array}$ \\
\hline 3 & 0.95 & 3.93 & 2.26 & 6.41 & 31.49 & $\begin{array}{l}\text { Diffuse compaction band+high-angle shear } \\
\text { band } 450\end{array}$ \\
\hline 4 & 1.45 & 2.24 & 2.20 & 13.88 & 33.80 & Discrete compaction band \\
\hline 5 & 0.95 & 4.27 & 2.37 & 6.88 & 31.84 & $\begin{array}{l}\text { Diffuse compaction band+high-angle shear } \\
\text { band } 600\end{array}$ \\
\hline 6 & 2.10 & 8.29 & 4.86 & 7.16 & 19.07 & Shear band \\
\hline 7 & 1.95 & 4.34 & 3.40 & 14.41 & 36.12 & Discrete compaction band \\
\hline 8 & 2.40 & 8.15 & 5.12 & 7.15 & 23.42 & Dilation+high angle surface cracks \\
\hline 9 & 2.90 & 10.01 & 6.24 & 7.33 & 23.47 & High-angle shear band 700 \\
\hline 10 & 0.95 & 0.66 & 1.17 & 13.26 & 44.11 & Discrete compaction band \\
\hline
\end{tabular}


considering the failure modes and differential stress-axial strain curves, the results are divided into three patterns except sample 8.

Samples 6 and 9 failed with a shear band and a high-angle shear band respectively. There are several stress drops on the differential stress-axial strain curves. The maximal stress drops are usually smaller, and only about $10 \%$ of the differential stress of the compactive yield. There are no distinct stress increases after the compactive yield. The porosity, confining pressure and strength of sample 8 are similar to these of samples 6 and 9, and the differential stress-axial strain curve is also similar to these of samples 6 and 9. But there is an obvious stress increase on the differential stressaxial strain curve of sample 8 when the axial strain is large, and the maximal stress drop is up to $21 \%$. The lateral surface of sample 8 dilates obviously after unloading, which is different from all other specimens. There are some highangle surface cracks on the surface of sample 8, but they are not across the specimens.

Samples 4, 7 and 10 failed with the form of discrete band, and all of them experienced unloading-reloading test. The maximal stress drops of differential stress-axial stress curves are bigger, and they are about $43 \%-65 \%$ of the differential stress of the compactive yield. The differential stresses have distinct increases after the compactive yield. There are no obvious stress drops on the differential stress-axial strain curves of samples 4 and 7 during the reloading process. But there are obvious stress drops on the differential stress-axial strain curve of sample 10 during reloading process. Therefore, it is speculated that the compaction bands of samples 4 and 7 were created in the first loading process, not in the reloading process. But the compaction bands of sample 10 were created in both loading processes. The compaction bands of sample 10 pervasively developed, and one end was greatly damaged.

Samples 1, 2, 3 and 5 failed with hybrid modes of two patterns among the three: discrete compaction band, diffuse compaction band and high-angle shear band. Sample 1 failed with the hybrid form of a discrete compaction band and a diffuse compaction band. Sample 2 failed with the hybrid form of a discrete compaction band and a high-angle shear band. Samples 3 and 5 failed with the hybrid form of a diffuse compaction band and a high-angle compaction band. The maximal stress drop of sample 1 is bigger, and up to $62 \%$. There is a distinct stress increase on the differential stress-axial strain curve of sample 1 after the compactive yield, which may be relate with the discrete compaction band. The maximal stress drops of sample 2, 3 and 5 are $30 \%-40 \%$ of the differential stress of the compactive yield. Samples 3 and 5 have no obvious stress increase after the compactive yield, but sample 2 has. The reason may be that sample 2 has a discrete compaction band. These four specimens have many big stress drops.

Figure 2 shows some representative results of failure modes. The compaction band shapes of samples 1 and 2 are straight, and the shape of sample 7 is fluctuated, as can be clearly observed. Baud et al. [2] also observed the local fluctuation of compaction bands in their experiment. Samples 1 and 2 are more homogenous compared to sample 7 from appearance. The fluctuation may be caused by local inhomogeneity.

The specimens with more stress drops have a diffuse compaction band (e.g., samples 1 and 5), or pervasive discrete compaction bands (sample 10). Vajdova and Wong. [21], and Tembe et al. [22] observed that every stress drop corresponds to a surge of acoustic emission activity. The stress drops are below $2 \mathrm{MPa}$ in this experiment, and they are smaller compared to other experiments. The two sides of diffuse compaction bands are separated after unloading, and the cemented grains are disaggregated inside compaction bands. There is no obvious disaggregation outside compaction bands. Grain crushing is not severe in the bands. The
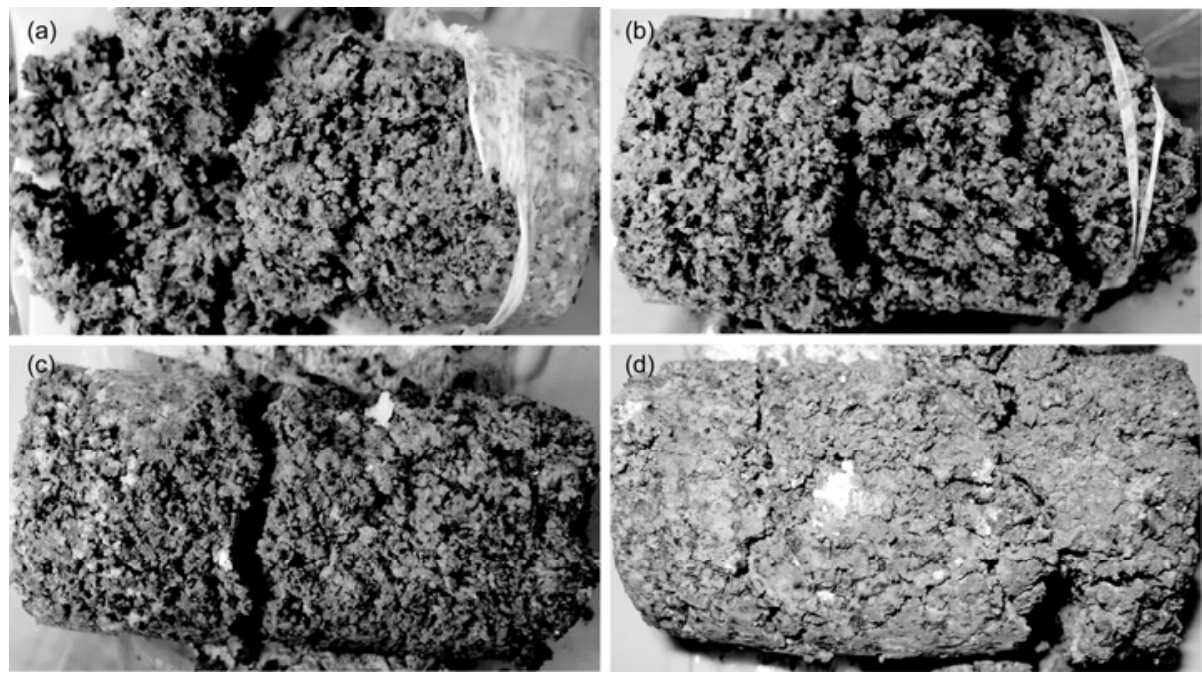

Figure 2 Failure modes of (a) sample 1, (b) sample 2, (c) sample 4 and (d) sample 7. 
discrete compaction bands of samples 1, 2, 4 and 7 are cracks mainly perpendicular to the axial stress direction, and the cracks cross through the specimens. These discrete compaction bands were formed by breaking cementation. There are no other disaggregating grains inside the discrete compaction bands. The grains within 1-2 grains diameter of discrete compaction bands were disturbed. The bands are very thin, which are about on the order of millimeter. So, grain crushing inside compaction bands is not intense in this experiment. The main mechanism of forming a compaction band is disaggregation by breaking cementation.

The results of failure modes are shown in Table 2 . Specimens with higher porosity, such as samples 4, 7 and 10 , are apt to form discrete compaction bands. Specimens with lower porosity are apt to form shear bands or highangle shear bands, such as samples 6 and 9, respectively. Specimens with intermediate porosity are apt to form a hybrid mode composed of two patterns of the high-angle shear band, diffuse compaction band and discrete compaction band. This is consistent with the conclusion of Baud et al. [2]. Porosity is not the only factor that affects the failure mode, and confining pressure also has a great influence. Sample 2 has a relatively higher porosity, but it failed with the hybrid form of a discrete compaction band and a high-angle shear band. This may be caused by the lower effective confining pressure. Through inspecting other specimens, it can be found that it is apt to involve high-angle shear bands in a hybrid mode when the effective confining pressure is lower. Therefore, it comes to the conclusion that lower porosity and effective confining pressure are helpful for forming shear bands or high-angle shear bands, higher porosity and effective confining pressure are helpful for forming discrete compaction bands, and intermediate porosity and effective confining pressure are helpful for forming a hybrid mode of two of the three of high-angle band, diffuse compaction band and discrete compaction band.

\subsection{Results of unloading-reloading}

The loads of samples 4, 7 and 10 were unloaded when the axial displacements were close to the extensometer's measuring range. After adjusting the extensometers, the confining pressure and pore pressure reached the values before unloading respectively. The representative differential stressaxial strain curves of reloading are shown in Figure 3. The strains in Figure 3 are relative to the specimen length before compression. The differential stresses of these three specimens firstly rise up almost rigidly. Then the differential stresses increase with larger slopes, which seems to be elastic deformation. After that, the differential stress curves of samples 4 and 7 are similar, but they are much different from that of sample 10. The differential stress curves of samples 4 and 7 have plateaus. When the differential stresses are closed to the values before unloading respectively, which are indicated by the circles in Figure 3, they begin to
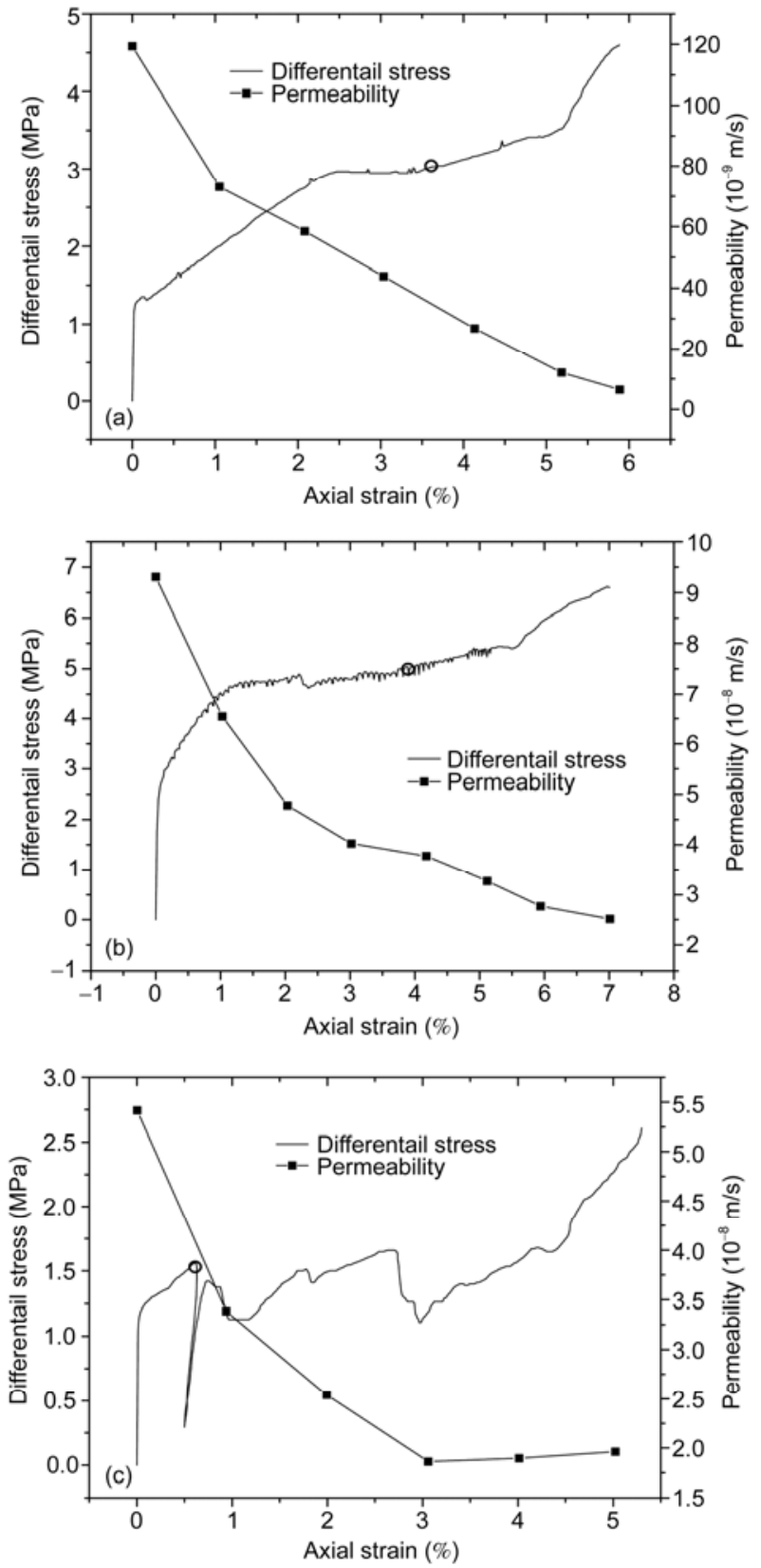

Figure 3 Reloading differential stress and permeability vs. axial strain of (a) sample 4, (b) sample 7 and (c) sample 10.

increase with smaller slopes. Then larger slope stress increases followed. There is no stress plateau before the differential stress of sample 10 reaches the stress beginning to unload. The following is an overall plateau with several bigger stress drops. Finally, it is a larger slope stress increase. Several bigger stress drops of sample 10 imply that localized bands formed in the process of reloading. There is an unloading-reloading process on the curve of sample 10. This never appears for other specimens. The shapes of the differential stress-axial strain curve of these three specimens are different from common shapes of differential stress-axial strain curves of low porosity rocks. The reason of almost 
rigid increase of differential stress-axial strain curves is that the stiffness had been greatly enhanced after the first process of compression. It is not clear whether the difference between the unloading-reloading process defined in this paper and the common unloading-reloading process leads to this difference.

\subsection{Permeability changes}

The variation of permeability is about three orders of magnitude in these specimens, and this is very huge. The representative permeability-axial strain curves are shown in Figure 1 . The permeability of every specimen degrades with the axial strain increase as a whole. The local permeability maybe increase, which reflects the complexity of deformation mechanism. This is consistent with other researcher's results [30-32]. The permeability degrades by no more than two orders of magnitude, and most of them are below one order of magnitude. It is lower than other experiments $[17,18]$, which were $2-3$ orders of magnitude. This is due to no obvious grain crushing in this experiment. The trends of permeability evolution have some differences among these specimens. The permeability evolution trends of samples 2, 6, 8, 9 and 10 are similar. They decrease with the increase of axial strains, and the speeds also decrease. After this stage, samples 1 and 4 have a sharp permeability decrease. Firstly, the permeabilities of samples 5 and 7 decrease slowly, and then decrease sharply, and at last the permeability decrease of sample 5 gets slowly, but sample 7 does not go so far.

\section{Discussions}

\subsection{Factors promote compaction band formation}

The stress levels of compaction band formation in other experiments were higher than the stress level inferred for compaction band formation in the field [3]. In this experiment, the maximal principal stresses for compaction band formation are below $8 \mathrm{MPa}$, which is much lower than other researchers' results and those in the field. The main reasons are that the porosities are much higher and the cementation strengths are much weaker compared to the rocks used in other experiments. The porosities of sandstones used in other experiments were 13\%-28\% [2, 6, 20, 22]. However, the porosities are $19 \%-44 \%$ in this study. Besides, the specimens are more heterogeneous in this experiment. Heterogeneity promotes stress concentration, which is favorable for localization band formation. The shapes of the discrete compaction bands shown in Figure 2 are somewhat wavy. The bands of relatively homogeneous specimens are more straight compared to relatively heterogeneous specimens. This indicates that the homogeneity indeed has a great impact on the development of discrete compaction bands.
The compaction bands of samples 4 and 7 are not at the sample ends. This indicates that the end stress concentration has little influence on their formation, and it is different from the results of specimens without notches in other experiments. The discrete compaction bands observed in this experiment are somewhat similar to those in a specimen with notches. Although, samples 4 and 7 are reloaded to a stage of obvious stress increase after unloading, there are only 1-2 discrete compaction bands in these two specimens. This result is different from the experiment of Wong et al. [7]. It may be because the surfaces of the specimens are very concave-convex, which makes them resemble specimens with notches. There is no obvious grain crushing inside the compaction bands in this experiment, and it is different from other experiments. The permeability reduction is also lower than in other experiments, and this is coincident with little comminution. Therefore, the mechanisms of compaction band formation in this experiment are not the same as other experiments. The formation of compaction bands is mainly by cementation breaking and pore collapse. The stresses didn't reach the level of grain crushing, and was very low. So, the grain crushing is not a necessary condition for compaction band formation. If the cementation strength is larger than the stress level for grain crushing, grain crushing becomes one of the main mechanisms for compaction band formation. When the cementation strength is close to the stress level of grain crushing, grain crushing may be not severe. In view of other experiments and results in the field, it could come to the conclusion that compaction bands can form by cementation breaking, grain crushing and pore collapse in a broad range of stress levels if the lithology and stress conditions are suitable. The discrepancies of intensity of grain crushing and stress levels for compaction band formation between laboratory results and observation in the field are understandable. In addition, it should be noticed that the time scale may be different between compaction band formation in laboratory and in the field. Compaction bands in the field may form by creeping in a long time. This may cause that the stress level for compaction band formation and the intension of grain crushing are low.

\subsection{Relationship between different types of compaction bands}

Louis et al. [33] speculated that high porosity and homogeneity are important conditions for producing compaction bands. The previous analysis in this paper indicates that higher porosity promotes discrete compaction band formation and intermediate porosity promotes diffuse compaction band formation. This is consistent with the result of Baud et al. [2]. Klein et al. [20] speculated that relatively homogeneous mineralogy and well-sorted grain sizes of Bentheim sandstone were preferential to develop discrete compaction bands. However, Diemelstadt sandstone has a similar porosity with Bentheim sandstone and relatively dispersive grain 
sizes, but it has a similar type of compaction bands with Bentheim sandstone. The grain size distributions of these two sandstones are both relatively narrow [2]. Based on these, Baud et al. [2] speculated that a diffuse compaction band was formed by coalescing short discrete compaction bands which were prevented by smaller pores and disperse grain sizes. The simulations of Katsman et al. [34] and Wang et al. [35] indicated that the growth of discrete compaction bands are promoted in relatively homogeneous rocks, and that diffuse compaction bands are preferential in more heterogeneity rocks. The mineralogy distribution of Bleurswille sandstone is also dispersive, and it can develop discrete compaction bands as well. But the distribution of its pores is homogeneous [25]. The previous analysis in this paper indicates that the stress drops during discrete compaction band formation are larger compared to diffuse compaction bands. It can be confirmed by observing the experiments of other researches [2, 20, 22, 36-40]. So, the development of discrete compaction bands is more instable. The homogeneity of pores and grains promotes instable development of localized bands. The heterogeneity of pores and grain sizes has a larger impact on stress concentration compared to mineralogy heterogeneity. The narrow distribution of grain sizes is favorable for forming homogeneous pores. So, relatively homogeneous pores and narrow distribution of grain sizes may promote the growth of discrete compaction bands, and relatively heterogeneous pores and disperse distribution of grain sizes may promote the development of diffuse compaction bands. But a discrete compaction band and a diffuse compaction band appeared in the same specimen in this experiment. This phenomenon was also found in the experiment of Baud et al. [2]. It can be speculated that homogeneity is not the sole factor affecting the patterns of compaction bands. So far, the cases of diffuse compaction bands are rare. From only a few cases, it can be found that if the two types of compaction bands appear in the same type rocks, then the diffuse compaction band or the hybrid mode of these two patterns can be formed at lower confining pressures and the discrete compaction band can be formed at higher confining pressures. Therefore, it is probable that failure modes change in the order of shear band, high-angle shear band, diffuse compaction band, discrete compaction band and uniform cataclastic flow with the confining pressure increase in the same type rocks. Some factors may make diffuse compaction bands disappear.

\section{Conclusions}

Researchers have observed compaction bands, which are analogous to those found in the field, but there are some differences in the aspects of formation stress levels, grain crushing intension and band thickness. We conducted triaxial compression tests on very low strength weathered porous rocks and observed discrete compaction bands, diffuse compaction bands and the hybrid modes. The stress levels of compaction band formation are no more than $8 \mathrm{MPa}$, and grain crushing in the bands is not severe. Permeability reductions are below 2 orders of magnitude, and most under 1 order of magnitude. This is lower than the results of other researches, because there is no severe grain crushing during the formation of bands. Cementation breaking is the main formation mechanism of compaction bands in experiments of this paper. Combined with other experiments, it can be concluded that compaction bands can form by the mechanisms of cementation breaking, grain crushing and pore collapse in a broad range of stress levels.

When confining pressures are in the brittle-ductile transition regime, high porosity is beneficial for the formation of discrete compaction bands, low porosity promotes the formation of high-angle shear bands, and intermediate porosity is favorable for the growth of hybrid modes. The confining pressure also has a great influence on the localization structure. Relatively homogenous rocks are prone to form discrete compaction bands, and relatively heterogeneous rocks are prone to form diffuse compaction bands. The formation process of discrete compaction bands is more unstable than that of diffuse compaction bands. Seen from the experiment results, these two types of bands can appear in one specimen, and diffuse compaction bands are easier to form under low confining pressures.

We appreciate WANG ZhongFu from North China University of Water Resource and Electric Power for helping with the experiments. We also thank SUN Liang from Ecole polytechnique fédérale de Lausanne and WANG SiJing from Tsinghua University for their suggestions to improve this paper. This work was supported the National Natural Science Foundation of China (Grant No. 51009079), National Basic Research Program of China ("973" Project) (Grant Nos. 2011CB013503, 2013CB035902), and Open Research Fund Program of State key Laboratory of Hydroscience and Engineering (Grant No. 2013-KY-6).

1 Mollema P N, Antonellini M A. Compaction bands: A structural analog for anti-mode I cracks in Aeolian sandstone. Tectonophysics, 1996, 267: 209-228

2 Baud P, Klein E, Wong T F. Compaction localization in porous sandstones: Spatial evolution of damage and acoustic emission activity. J Struct Geol, 2004, 26: 603-624

3 Holcomb D, Rudnicki J W, Issen K A, et al. Compaction localization in the Earth and the laboratory: State of the research and research directions. Acta Geotech, 2007, 2: 1-15

4 Wong T F, Baud P. Grain crushing, pore collapse and strain localization in porous sandstone. Mechanics of Natural Solids. Berlin Heidelberg: Springer-Verlag, 2009. 239-254

5 Olsson W A. Theoretical and experimental investigation of compaction bands in porous rock. J Geophys Res, 1999, 104: 7219-7228

6 Olsson W A, Holcomb D J. Compaction localization in porous rock. Geophys Res Lett, 2000, 27: 3537-3540

7 Wong T F, Baud P, Klein E. Localized failure modes in a compactant porous rock. Geophys Res Lett, 2001, 28: 2521-2524

8 Haimson B C. Borehole breakouts in Berea sandstone reveal a new fracture mechanism. Pure Appl Geophys, 2003, 160: 813-831

9 Haimson B, Kovacich J. Borehole instability in high-porosity Berea sandstone and factors affecting dimensions and shape of fracture-like breakouts. Eng Geol, 2003, 69: 219-231 
10 Haimson B. Fracture-like borehole breakouts in high-porosity sandstone: Are they caused by compaction bands?. Phys Chem Earth, 2001, 26: 15-20

11 Haimson B, Lee H. Borehole breakouts and compaction bands in two high-porosity sandstones. Int J Rock Mech Min, 2004, 41: 287-301

12 Fôrtin J, Sanchits S, Dresen G, et al. Acoustic emission and velocities associated with the formation of compaction bands in sandstone. $\mathrm{J}$ Geophys Res, 2006, 111: B10203

13 Wong T F, Baud P. Mechanical compaction of porous sandstone. Oil Gas Sci Technol, 1999, 54: 715-727

14 Townend E, Thompson B D, Benson P M, et al. Imaging compaction band propagation in Diemelstadt sandstone using acoustic emission locations. Geophys Res Lett, 2008, 35: L15301

15 Stanchits S, Fortin J, Gueguen Y, et al. Initiation and propagation of compaction bands in dry and wet Bentheim sandstone. Pure Appl Geophys, 2009, 166: 843-868

16 Charalampidou E M, Hall S A, Stanchits S, et al. Characterization of shear and compaction bands in a porous sandstone deformed under triaxial compression. Tectonophysics, 2011, 503: 8-17

17 Holcomb D J, Olsson W A. Compaction localization and fluid flow. J Geophys Res, 2003, 108: B62290

18 Vajdova V, Baud P, Wong T F. Permeability evolution during localized deformation in Bentheim sandstone. J Geophys Res, 2004, 109: B10406

19 Sternlof K R, Rudnicki J W, Pollard D D. Anticrack inclusion model for compaction bands in sandstone. J Geophys Res, 2005, 110: B11403

20 Klein E, Baud P, Reuschle T, et al. Mechanical behavior and failure mode of Bentheim sandstone under triaxial compression. Phys Chem Earth, 2001, 26: 21-25

21 Vajdova V, Wong T F. Incremental propagation of discrete compaction bands: acoustic emission and microstructural observations on circumferentially notched samples of Bentheim sandstone. Geophys Res Lett, 2003, 30: 1775

22 Tembe S, Vajdova V, Wong T F, et al. Initiation and propagation of strain localization in circumferentially notched samples of two porous sandstones. J Geophys Res, 2006, 111: B02409

23 Loaiza S, Fortin J, Schubnel A. Mechanical behavior and localized failure modes in a porous basalt from the Azores. Geophys Res Lett, 2012, 39: L19304

24 Schultz R A, Soliva R. Propagation energies inferred from deformation bands in sandstone. Int J Fract, 2012, 176: 135-149

25 Tembe S, Baud P, Wong T F. Stress conditions for the propagation of discrete compaction bands in porous sandstone. J Geophys Res, 2008, 113: B09409

26 Bqxevqnis T, Papamichos E, Flornes O, et al. Compaction bands and induced permeability reduction in Tuffeau de Maastricht Calcarenite.
Acta Geotech, 2006, 1: 123-135

27 Rudnicki J W. Models for compaction band propagation. In: Rock Physics and Geomechanics in the Study of Reservoirs and Repositories. London: Geological Society of London Special Publication, 2007. 284

28 Zhu W, Wong T F. The transition from brittle faulting to cataclastic flow: Permeability evolution. J Geophys Res, 1997, 102: 3027-3041

29 Cheung C S N, Baud P, Wong T F. Effect of grain size distribution on the development of compaction localization in porous sandstone. Geophys Res Lett, 2012, 39: L21302

30 Sun W, Andrade J E, Rudnicki J W, et al. Connecting microstructural attributes and permeability from 3D tomographic images of in situ shear-enhanced compaction bands using multiscale computations. Geophys Res Lett, 2011, 38: L10302

31 Ballas G, Soliva R, Sizun J P, et al. Shear-enhanced compaction bands formed at shallow burial conditions; implications for fluid flow (Provence, France). J Struct Geol, 2013, 47: 3-15

32 Meredith P, Baud P, Heap M J. et al. Influence of compaction bands and stylolites on the permeability of porous rocks. In: Flows and Mechanics in Natural Porous Media from Pore to Field Scale. Pore2Field. France: IFP Energies nouvelles, 2011

33 Louis L, Baud P, Wong T F. Compaction localization in high porosity sandstones with various degrees of heterogeneity: insight from X-ray computed tomography. In: ROCKEN09: Proceedings of the 3rd CANUS Rock Mechanics Symposium. Toroto, 2009

34 Katsman R, Aharonov E, Scher H. Numerical simulation of compaction bands in high porosity sedimentary rock. Mech Mater, 2005, 37: 143-162

35 Wang B, Chen Y, Wong T F. Adiscrete element model for the development of compaction localization in granular rock. J Geophys Res, 2008, 113: B03202

36 Louis L, Wong T F, Baud P, et al. Imaging strain localization by Xray computed tomography: discrete compaction bands in Diemelstadt sandstone. J Struct Geol, 2006, 28: 762-775

37 Pons A, David C, Fortin J, et al. X-ray imaging of water motion during capillary imbibition: A study on how compaction bands impact fluid flow in Bentheim sandstone. J Geophys Res, 2011, 116: B03205

38 Charalampidou E M, Hall S A, Stanchits S, et al. Shear-enhanced compaction band identification at the laboratory scale using acoustic and full-field methods. Int J Rock Mech Min, 2013, http://dx.doi.org/ 10.1016/j.ijrmms.2013.05.006i

39 Schultz R A. Relationship of compaction bands in Utah to Laramide fault-related folding. Earth Planet Sc Lett, 2011, 304: 29-35

40 Chemenda A I. Origin of compaction bands: Anti-cracking or constitutive instability?. Tectonophysics, 2011, 499: 156-164 